\title{
Measurement of Trabecular Bone Score of the spine by low-dose imaging system $\left(\mathrm{EOS}^{\circledR}\right)$; a feasibility study.
}

\author{
S. Kolta ${ }^{1,2}$, A. Etcheto ${ }^{2}$, J. Fechtenbaum ${ }^{1}$, A. Feydy ${ }^{2,3,4}$, C. Roux ${ }^{1,2,4}$, K. Briot ${ }^{1,2}$. \\ 1. Department of Rheumatology, Cochin Hospital, Assistance Publique- Hôpitaux de Paris, Paris, France. \\ 2. INSERM UMR-1153, Paris, France. \\ 3. Department of Radiology B, Cochin Hospital, Assistance Publique- Hôpitaux de Paris, Paris, France. \\ 4. Paris-Descartes University, Paris, France.
}

Corresponding author: Sami Kolta, MD

Address: Cochin hospital, Rheumatology department

27 rue du faubourg saint Jacques

75014 Paris, France

e.mail: sami.kolta@aphp.fr 
Measurement of Trabecular Bone Score of the spine by low-dose imaging system (EOS $\left.{ }^{\varpi}\right)$; a feasibility study. 
Key words: TBS; EOS; Fracture; Osteoporosis

\title{
Mini-abstract
}

This is the first study evaluating the feasibility of the measurement of trabecular bone score $\left(\mathrm{TBS}^{\circledR}\right)$ of the lumbar spine on the low-dose imaging system $\left(\mathrm{EOS}^{\circledR}\right)$. Results show that measurement of $\mathrm{TBS}^{\circledR}$ on $\mathrm{EOS}^{\circledR}$ is feasible. Some technical issues need to be solved before its eventual use in routine clinical settings.

\begin{abstract}
Purpose/Introduction: Measurement of trabecular bone score $\left(\mathrm{TBS}^{\circledR}\right)$ of the lumbar spine on DXA devices improves fracture risk prediction. We conducted a proof of concept study to assess the feasibility of $\operatorname{TBS}^{\circledR}$ measured on the low-dose imaging system EOS $^{\circledR}$. Methods: TBS was assessed on both DXA and $\mathrm{EOS}^{\circledR}$ in 122 patients aged $\geq 50$ years, receiving no antiosteoporotic treatment. The $\mathrm{TBS}^{\circledR}$ was computed on full-body $\mathrm{EOS}^{\circledR}$ images, focusing on the lumbar spine region. The patients were also scanned with a DXA bone densitometer (Hologic) and the spine and hip bone mineral density (BMD, $\mathrm{g} / \mathrm{cm}^{2}$ ) were computed. Results: TBS $^{\circledR}$ measurement on EOS $^{\circledR}$ was not possible in 34 patients due to technical problems. It could be measured on both DXA and $\operatorname{EOS}^{\circledR}$ in 88 patients $(28$ with severe low-trauma fracture, and 60 without fracture). TBS-EOS values were significantly lower in fractured patients compared to non-fractured patients. TBS-EOS was associated with the presence of fractures as reported by an AUC of 0.70. Odds ratio of TBS-EOS for the presence of severe low-trauma fracture was 2.00 [1.24 - 3.25], p=0.005. Conclusions: This proof of concept study, based on a prototype version of the TBS-EOS, demonstrated the feasibility of the measurement of $\mathrm{TBS}^{\circledR}$ on low-dose EOS $^{\circledR}$ imaging devices. Results show that the TBS-EOS was lower in patients with severe low-trauma fractures compared to non-fractured patients independently from BMD. Some technical issues need to be solved before its eventual use in routine clinical settings. Additional prospective studies are still needed to define the actual contribution of this new technique.
\end{abstract}




\section{Introduction}

Spine radiographs are performed daily for various medical reasons, including diagnosis of degenerative spine diseases and vertebral fractures. EOS $^{\circledR}$ is an X-ray imaging system, which allows the acquisition of biplane images of the skeleton while the patient is in an upight position. It appears to have some advantages over the currently available technologies of spine imaging such as full body imaging without digital stitching, simultaneous posteroanterior and lateral images, and lower radiation dose (50-80\% less than conventional X-rays) (1). In the management of osteoporosis, $\operatorname{EOS}^{\circledR}$ radiographs give the opportunity to assess both the vertebral bodies' deformities and fractures, and the spinal curvatures in weight bearing position (2,3). These data are already available and are the opportunity to get potential information on osteoporosis with no additional cost or patient time. Adding another parameter related to fracture risk could improve patient management. The Trabecular Bone Score $\left(\mathrm{TBS}^{\circledR}\right)$ is a grey-level bone texture measurement, currently used on images of dual energy xray absorptiometry (DXA) measurement of the lumbar spine. Cross-sectional studies showed that TBS $^{\circledR}$ calculated on DXA imaging is lower in post-menopausal women with low-trauma fracture compared to those without fracture $(4,5)$, and is lower in women with fractures irrespective of whether their bone mineral density $\left(\mathrm{BMD}, \mathrm{g} / \mathrm{cm}^{2}\right)$ met the criteria for osteoporosis or osteopenia $(6,7)$. Combining TBS $^{\circledR}$ and lumbar spine BMD improved fracture prediction with a better performance than $\mathrm{TBS}^{\circledR}$ or spine BMD alone (8) and similar to hip BMD (9). Lumbar spine texture analysis using $\mathrm{TBS}^{\circledR}$ has also been incorporated in fracture risk prediction using the FRAX $^{\circledR}$ method (10-12).

The aim of this study was to assess the feasibility of measurement of $\mathrm{TBS}^{\circledR}$ on images of the lumbar spine obtained with EOS $^{\circledR}$ (TBS-EOS) in a population of patients with and without osteoporotic fractures.

\section{Patients and Methods}

This is a proof of concept monocentric study with consecutive, prospective inclusion of patients followed at our center (a tertiary health center). The protocol is a part of a larger project on fracture risk assessment in adults by $\mathrm{EOS}^{\circledR}$ by micro- and macro-architectural analysis that was approved by CPP Île de France VI ethics committee on 10th January 2007. Male and female patients having had BMD measurement and an $\mathrm{EOS}^{\circledR}$ image in our center from April 2014 till March 2015 were included in the study. The inclusion criteria were age above 50 years old and the absence of anti-osteoporotic treatment in the past year. Fractured 
and non-fractured patients were paired for body mass index (BMI, $\mathrm{kg} / \mathrm{m}^{2}$ ) and age. Vertebral fractures were confirmed by a senior rheumatologist specialized in osteoporosis. Non vertebral fractures were documented by radiographs.

BMD of the lumbar spine (L2-L4) and left hip was measured using a Hologic QDR 4500A device (Hologic, Walhtham, MA). Positioning of the patients and analysis of the scans were done according to the manufacturer's recommendations. Quality control of the device was done using a Hologic phantom every day where a patient was scanned and at least 3 times weekly.

$\mathrm{TBS}^{\circledR}$ of lumbar vertebrae (L2-L4) was measured by the manufacturer on DXA using TBS iNsight v2.2. It was also measured by 2 different observers on $\operatorname{EOS}^{\circledR}$ images blinded to the results of BMD. A dedicated TBS $^{\circledR}$ software was developed for EOS $^{\circledR}$ images. The TBS-EOS was integrated on an $\operatorname{EOS}^{\circledR}$ software prototype allowing computing and displaying TBS $^{\circledR}$ values and maps along with sterEOS ${ }^{\mathrm{TM}}$ numerical models of the spine. As a prototype, TBSEOS does not include a soft-tissue compensation system, and the TBS-EOS values are not designed to be in the same range as TBS $^{\circledR}$ values computed on DXA systems. TBS ${ }^{\circledR}$ was calculated on postero-anterior view of the first four lumbar vertebrae. It was computed on a rectangular projected area, the largest fitting in between upper and lower vertebral endplates (Figure 1). This area was retrieved from the plain projection of the 3D reconstruction of the spine using sterEOS ${ }^{\mathrm{TM}}$ software. Vertebrae were excluded from the analysis when vertical vertebral rotation exceeded $22^{\circ}$. This threshold was fixed as the limit allowing to have an area of at least $33 \%$ of the maximal projected surface area of the vertebra (figure 2). This $33 \%$ threshold was set arbitrary in order to get an area representative of the whole vertebra. Another exclusion criterion of $\mathrm{TBS}^{\circledR}$ calculation was an axial rotation of $>10^{\circ}$, which corresponds to the maximal axial rotation of the vertebra with non-significant effect on TBS $^{\circledR}$ result, defined by a variation less than a root mean square-SD of $\mathrm{TBS}^{\circledR}$ result compared to that obtained in the absence of vertebral rotation. These 2 thresholds were derived from technical ex-vivo experiments done by the manufacturer (unpublished data). Insufficient signal to noise ratio due to a soft tissue abdominal thickness, or the presence of gas or fat folds in front of vertebral bodies leading to a bad image quality, as evaluated by an expert, led to the exclusion of the corresponding vertebrae in this study, as their effect has not yet been quantified on EOS $^{\circledR}$ imaging systems. In all cases, appropriate region of interest positioning on at least 2 vertebrae was required for including the patient in the analysis. We have tested patient positioning as a source of variability that could affect TBS-EOS result in 34 patients who had 
two EOS measurements the same day in two different positions, one in a free standing position and the other while holding a fixed horizontal bar.

\section{Statistical analysis}

The statistical analysis was done independently from the manufacturers. Differences between patient groups were analysed by non-parametric Wilcoxon tests. Correlations between total hip, femoral neck, lumbar spine BMDs, with TBS $^{\circledR}$ measured by DXA and EOS ${ }^{\circledR}$ were calculated with the Spearman's correlation coefficient. Discriminative value of BMD at all bone sites and $\mathrm{TBS}^{\circledR}$ measured with $\mathrm{EOS}^{\circledR}$ and DXA was assessed by determining the area under the receiving operator characteristic (ROC) curve. Odds ratios of $\mathrm{TBS}^{\circledR}$ as well as BMD for the presence of severe low-trauma fractures were also calculated. The effect of patient position on TBS-EOS was calculated using the coefficient of variation $(\mathrm{CV}, \%)$, and plotted using the Bland and Altman method.

\section{Results}

\section{Feasibility of TBS measurement:}

One hundred and twenty two patients were included (Figure 3). For technical reasons, TBS ${ }^{\circledR}$ calculation was not possible in 34 patients $(28 \%)$ on EOS $^{\circledR}$. The main causes of $\mathrm{TBS}^{\circledR}$ calculation failure were vertical vertebral rotation $>22^{\circ}$ or axial angle $>10^{\circ}(\mathrm{N}=13)$, the presence of gas $(\mathrm{N}=4)$, fat folds in front of vertebral bodies $(\mathrm{N}=1)$ or insufficient signal to noise ratio $(\mathrm{N}=4)$ or a combination of these causes $(\mathrm{N}=12)$. There was no difference between patients whose $\mathrm{TBS}^{\circledR}$ could be measured or not concerning age, gender, weight, height, prevalence of osteoporosis and BMD (data not shown).

\section{Effect of patient positioning on TBS result:}

The coefficient of variation of TBS-EOS in 34 patients measured in two different positions, free standing position and holding a fixed horizontal bar, was 5.0\%. Results were highly correlated $\left(\mathrm{r}^{2}=0.85\right)$. The comparison of the results in both positions is illustrated by Bland and Altman plot in figure 4.

\section{TBS results:}

The remaining 88 patients had TBS $^{\circledR}$ measured on DXA and EOS ${ }^{\circledR}$. Among them, 28 patients had at least 1 severe low-trauma fracture (12 vertebral, 9 humeral, 3 hip, 4 tibial fractures) and 60 patients had no low-trauma fractures. TBS-EOS could be measured on 2 and 3 vertebrae only for 28 and 29 patients respectively. It could be measured on the 4 lumbar vertebrae for 31 patients. The main characteristics of the patients are summarized in Table 1. The comparison of the results according to the number of vertebrae analysed for TBS-EOS revealed no significant difference (Table 2). There was no statistically significant difference 
between patients with and without severe low-trauma fractures concerning age, weight, height and BMD. The prevalence of osteoporosis by DXA (at least one site with T-score $\leq-2.5$ ) was comparable in fractured and non-fractured patients. Twenty seven patients had T-scores higher than -2.5 at all the 3 sites (lumbar spine, femoral neck and total hip), and 10 of them had fractures: thus, $35.7 \%$ of the fractured population had a T-score which does not reach the osteoporotic BMD threshold.

Mean TBS-DXA and TBS-EOS were $1.167 \pm 0.085$ vs $1.224 \pm 0.098(\mathrm{p}=0.05)$ and $0.664 \pm 0.140$ vs $0.757 \pm 0.127$ ( $\mathrm{p}=0.003$ ) for patients with and patients without severe lowtrauma fractures respectively. Results remained significant even after adjustment on age (both $\mathrm{p}=0.008)$. There was no statistical difference between both groups for the BMI $\left(\mathrm{kg} / \mathrm{m}^{2}\right)$ and BMD. TBS-EOS was not correlated to spine BMD ( $\mathrm{r}=-0.19, \mathrm{p}=0.09)$. It was weakly but significantly and negatively correlated to the femoral neck and total hip BMD ( $\mathrm{r}=-0.32$, $\mathrm{p}=0.003$ and $\mathrm{r}=-0.27, \mathrm{p}=0.01$ respectively). TBS-EOS and TBS-DXA were significantly correlated $(\mathrm{r}=0.53 \mathrm{p}=0.0001)$. Results of TBS-EOS were systematically lower than TBSDXA. . Areas under ROC curve for TBS-EOS and TBS-DXA were respectively 0.70 and 0.63. They were $0.53,0.54$ and 0.53 for the BMD of the lumbar spine, total hip and femoral neck respectively. Odds ratio of TBS-EOS and TBS-DXA for the presence of severe lowtrauma fracture were respectively 2.00 [1.24 - 3.25], $\mathrm{p}=0.005$ and 1.98 [1.15 - 3.39], $\mathrm{p}=0.013$. Those of BMD of the lumbar spine, total hip and femoral neck were respectively 1.12 [0.70 1.78], 0.92 [0.58 - 1.46] and 1.21 [0.74 - 1.97] (all, $\mathrm{p}=\mathrm{NS}$ ).

\section{Discussion}

This proof of concept study shows the feasibility of $\mathrm{TBS}^{\circledR}$ computation on single-energy digital low-dose radiograph system $\left(\operatorname{EOS}^{\circledR}\right)$. It is weakly correlated to BMD and therefore may provide different information. However, some technical problems remain to be solved. $\mathrm{EOS}^{\circledR}$ is a novel technique of radiograph having the advantage of very low radiation to the patient compared to conventional radiographs. It allows the detection of several risk factors of fractures in the same setting. The presence of vertebral fractures as well as their number and severity are important risk factors for future low-trauma fractures (13). EOS $^{\circledR}$ allows their diagnosis (14) with up to $85 \%$ less dose to the patient than computed radiography (15). It is done in the standing weight bearing position acquiring postero-anterior and lateral views simultaneously and offering the opportunity to assess spine and pelvic curvatures. Measurement of these curvatures is also important to predict their different biomechanical effects on the vertebrae increasing the stress and therefore the risk of vertebral fracture (3). 
Finite element analysis can be also calculated on EOS images (16). There is also a development of bone mineral density measurement with this device (17). Adding to these parameters the measurement of a bone parameter as the $\mathrm{TBS}^{\circledR}$ could be a convenient way to add information on fracture risk. As for TBS-DXA, it can be calculated a posteriori on already existing EOS images. In our population, aged 65 years on average, it was not possible to measure $\mathrm{TBS}^{\circledR}$ on $\mathrm{EOS}^{\circledR}$ images in $28 \%$ of patients, due to technical reasons such as scoliosis, vertebral axial rotation, the presence of artefacts or bad image quality, gas projection or high soft tissue thickness. This high percentage precludes its current use in routine clinical settings and necessitates to be reduced by technical improvements. The compensation of the effects of scan parameters $(\mathrm{kV}, \mathrm{mA}$, acquisition time) is included in this prototype version of TBS on EOS. That of the effects of soft tissues is still to be included. Adequate range of scan parameters for a given patient has to be defined in order to obtain an adequate signal to noise ratio for bone texture evaluation using $\operatorname{TBS}^{\circledR}$.

In our population, $\mathrm{TBS}^{\circledR}$ measured on $\mathrm{EOS}^{\circledR}$ and on DXA were significantly but weakly correlated. This can be explained by the difference in patient positioning (supine position in DXA and standing position in EOS $^{\circledR}$ ). The supine position with leg elevation on a cushion in DXA, leads to correction of the lumbar lordosis, which is increased in the standing position in $\operatorname{EOS}^{\circledR}$. The supine position leads also to the spreading of the abdominal soft tissue to the sides of the patient and thus decreasing the soft tissue thickness in front of the lumbar vertebrae. However, in the standing position, the soft tissue is projected with skin folds in front of the vertebrae. In an ex-vivo study done by the manufacturer comparing TBS $^{\circledR}$ calculated on dry vertebrae using $\operatorname{EOS}^{\circledR}$ and different DXA devices, results were highly correlated $\left(r^{2}=0.90\right.$ to 0.98) (unpublished data). The different range of values ensures that $\mathrm{TBS}^{\circledR}$ reference curves for DXA cannot be used with TBS-EOS scores until the algorithm is ready for clinical use and specific normal values evaluated on EOS $^{\circledR}$ devices will be most probably needed.

Surprisingly, TBS-EOS was negatively correlated with BMD values. This may be explained by the fact that $\mathrm{TBS}^{\circledR}$ values on $\mathrm{EOS}^{\circledR}$ were not corrected for soft tissue thickness. TBS ${ }^{\circledR}$ is negatively correlated with soft tissue thickness as it brings noise to the image, while BMD is positively correlated to soft tissue thickness. Vertebrae with skin folds visible over them have been excluded from this study, but the effects of these folds on $\mathrm{TBS}^{\circledR}$ have yet to be quantified. There is the same issue with the effects of gas visible over the vertebrae.

Our study is the first dealing with measurement of $\mathrm{TBS}^{\circledR}$ of lumbar vertebrae on images acquired by an $\operatorname{EOS}^{\circledR}$ device. We carefully dealt with the selection of untreated patients at least for one year. It has some limitations, being a cross-sectional monocentric study with a 
limited number of patients and dealing with severe osteoporotic fractures only. In order to be able to use the $\mathrm{TBS}^{\circledR}$ values, population-specific reference curves and thresholds will have to be available for EOS $^{\circledR}$, as those developed on DXA cannot be used. TBS-EOS results were lower in patients with osteoporotic fractures than in those without fractures. However, our results cannot be generalized to the general population due to our small number of patients and the high percentage of patients in whom TBS-EOS could not be measured.

In conclusion, this proof of concept study suggests that measurement of $\mathrm{TBS}^{\circledR}$ on $\mathrm{EOS}^{\circledR}$ images is feasible but technical problems still need to be solved. Additional prospective studies after technical improvements and a larger number of patients are still needed to define the real contribution of this new technique.

\section{Acknowledgement:}

We acknowledge the assistance of Mr Franck Michelet, Ms Doris Tran and Mr Christophe Lelong from Medimaps, Mérignac, France for their technical help and the analysis of TBS on DXA scans and EOS images.

Sami Kolta, Adrien Etcheto, Jacques Fechtenbaum, Antoine Feydy, Christian Roux and Karine Briot declare that they have no conflict of interest 


\section{References}

1. Melhem E, Assi A, El Rachkidi R, Ghanem I. EOS_biplanar X-ray imaging: concept, developments, benefits, and limitations. J Child Orthop 2016; 10: 1-14.

2. Wade R, Yang H, McKenna C, Faria R, Gummerson N, Woolacott N. A systematic review of the clinical effectiveness of EOS 2D/3D X-ray imaging system. Eur J Spine 2013; 22: 296-304.

3. Fechtenbaum J, Etcheto A, Kolta S, Feydy A, Roux C, Briot K. Sagittal balance of the spine in patients with osteoporotic vertebral fractures. Osteoporos Int. 2016; 27: 559567.

4. Rabier B, Héraud A, Grand-Lenoir C, Winzenrieth R, Hans D. A multicentre, retrospective case-control study assessing the role of trabecular bone score (TBS) in menopausal Caucasian women with low areal bone mineral density (BMDa): Analysing the odds of vertebral fracture. Bone 2010; 46: 176-181.

5. Pothuaud L, Barthe N, Krieg MA, et al. Evaluation of the Potential Use of Trabecular Bone Score to Complement Bone Mineral Density in the Diagnosis of Osteoporosis: A Preliminary Spine BMD-Matched, Case-Control Study. J Clin Densitom 2009; 12: 170-176.

6. Winzenrieth R, Dufour R, Pothuaud L, Hans D. A Retrospective Case-Control Study Assessing the Role of Trabecular Bone Score in Postmenopausal Caucasian Women with Osteopenia: Analyzing the Odds of Vertebral Fracture. Calcif Tissue Int 2010; 86: 104-109.

7. Nassar K, Paternotte S, Kolta S, Fechtenbaum J, Roux C, Briot K. Added value of trabecular bone score over bone mineral density for identification of vertebral fractures in patients with areal bone mineral density in the non-osteoporotic range. Osteoporos Int. 2014; 25: 243-9

8. Del Rio LM, Winzenrieth R, Cormier C, Di Gregorio S. Is bone microarchitecture status of the lumbar spine assessed by TBS related to femoral neck fracture? A Spanish case-control study. Osteoporos Int 2013; 24: 991-998.

9. Briot K, Paternotte S, Kolta S, Eastell R, Reid DM, Felsenberg D, Glüer CC, Roux C. Added value of trabecular bone score to bone mineral density for prediction of osteoporotic fractures in postmenopausal women: the OPUS study. Bone. 2013; 57: 232-6. 
10. Kanis JA, Johnell O, Oden A, Johansson H, McCloskey E. FRAX and the assessment of fracture probability in men and women from the UK. Osteoporos Int 2008; 19:385397.

11. McCloskey EV, Odén A, Harvey NC, Leslie WD, Hans D, Johansson H, et al. A Meta-Analysis of Trabecular Bone Score in Fracture Risk Prediction and Its Relationship to FRAX. J Bone Miner Res 2016; 31: 940-948.

12. Couraud G, Souffir C, Gaigneux E, Kolta S, Roux C, Briot K. Adjusting FRAX® on TBS for identification of subjects at high risk of fractures. Bone 2017; 101: 214-218.

13. Kerkeni S, Kolta S, Fechtenbaum J, Roux C. Spinal deformity index (SDI) is a good predictor of incident vertebral fractures. Osteoporos Int. 2009; 20: 1547-1552.

14. Briot K, Fechtenbaum J, Etcheto A, Kolta S, Feydy A, Roux C. Diagnosis of vertebral fractures using a low-dose biplanar imaging system. Osteoporos Int. 2015; 26: 26492655.

15. Deschênes S, Charron G, Beaudoin G, Labelle H, Dubois J, MironMC. Diagnostic imaging of spinal deformities: reducing patients radiation dose with a new slot scanning X-ray images. Spine. 2010 Apr 20;35(9):989-94. doi: 10.1097/BRS.0b013e3181bdcaa4.

16. Sapin-de Brosses E, Jolivet E, Travert C, Mitton D, Skalli W. Prediction of the vertebral strength using a finite element model derived from low-dose biplanar imaging: benefits of subject-specific material properties. Spine (Phila Pa 1976). 2012 Feb 1; 37(3):E156-62. doi: 10.1097/BRS.0b013e3182293628.

17. Sapin E, Briot K, Kolta S, Gravel P, Skalli W, Roux C, Mitton D. Bone mineral density assessment using the EOS low-dose X-ray device: a feasibility study. Proc Inst Mech Eng H. 2008 Nov;222(8):1263-71. 
Figure 1: Region of interest of TBS-EOS, calculated in a rectangular projected area between upper and lower vertebral endplates. The size of the region of interest is different due to a different angle of vertical vertebral rotation due to lumbar lordosis in the standing position.

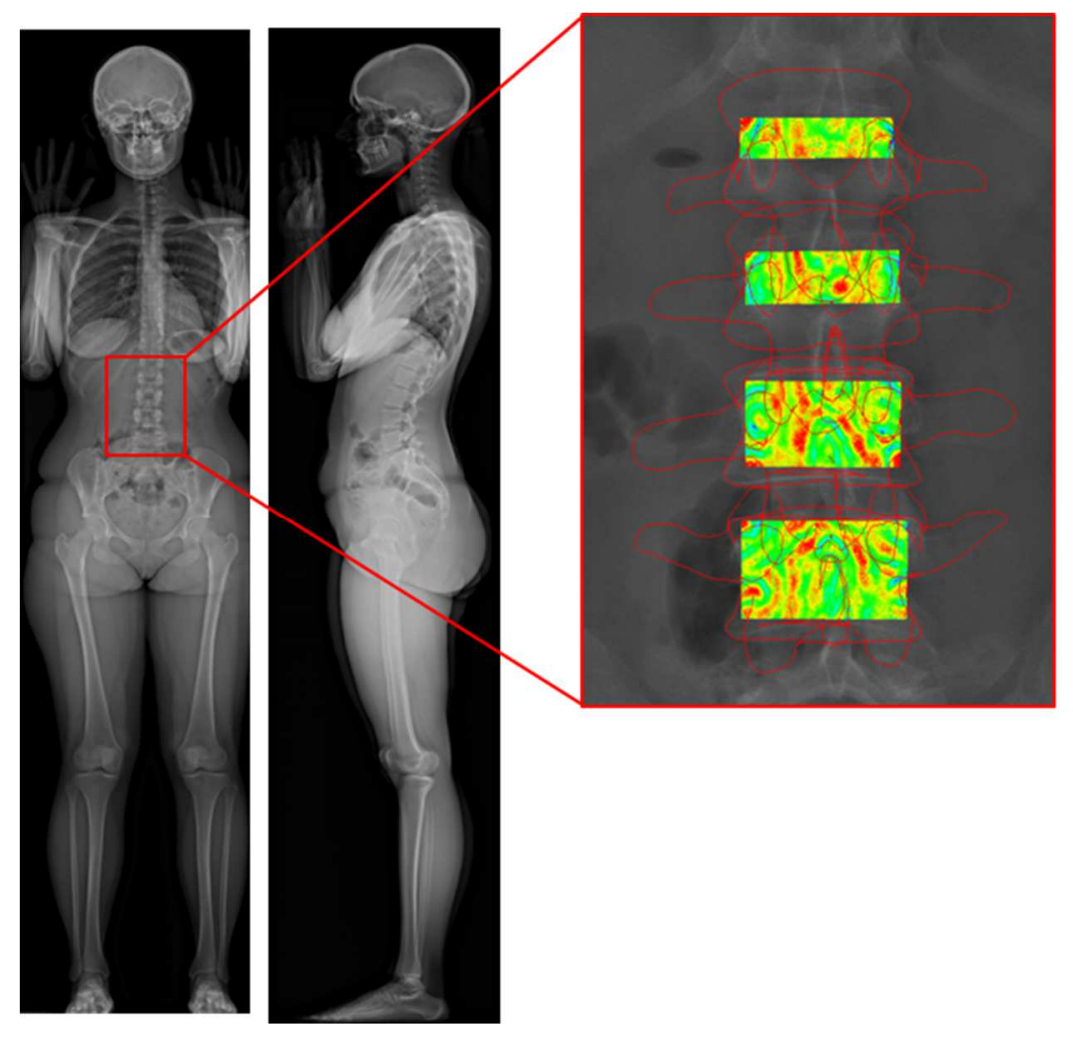


Figure 2: Vertical vertebral rotation. A vertical vertebral rotation less than $22^{\circ}$ was necessary for inclusion. This threshold was fixed as the limit that allows having an area of at least 33\% of the maximal surface area of the vertebra.

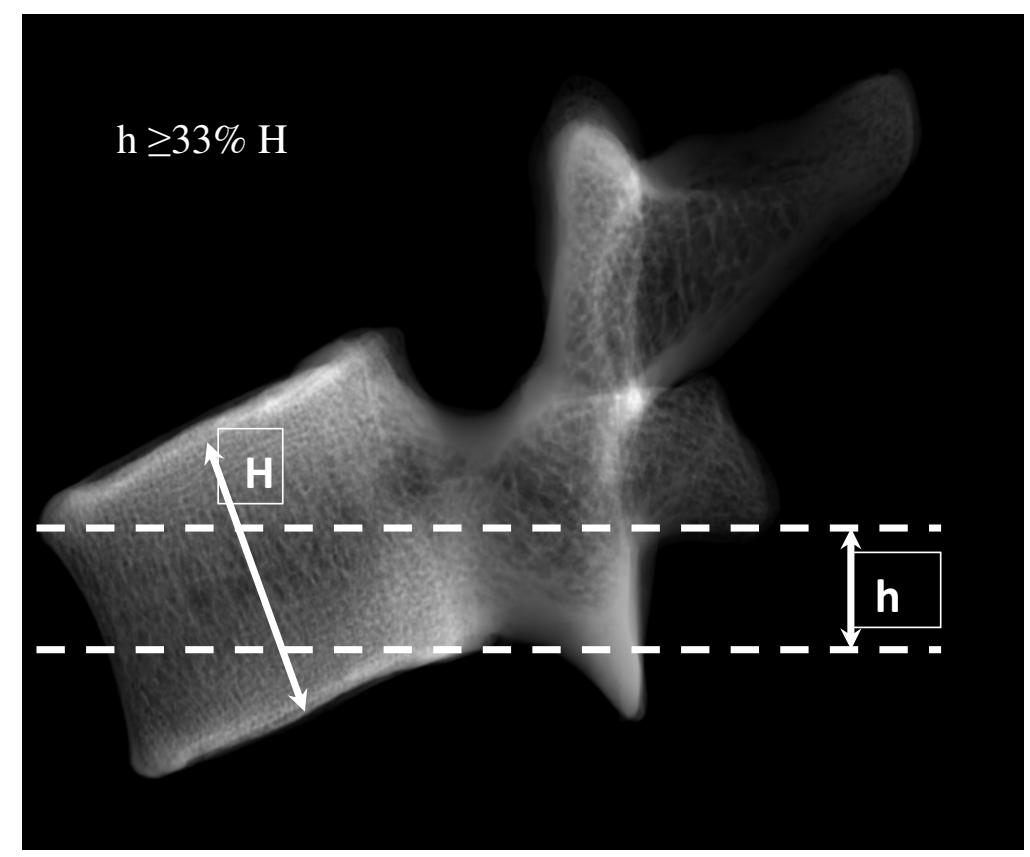


Figure 3: Flowchart

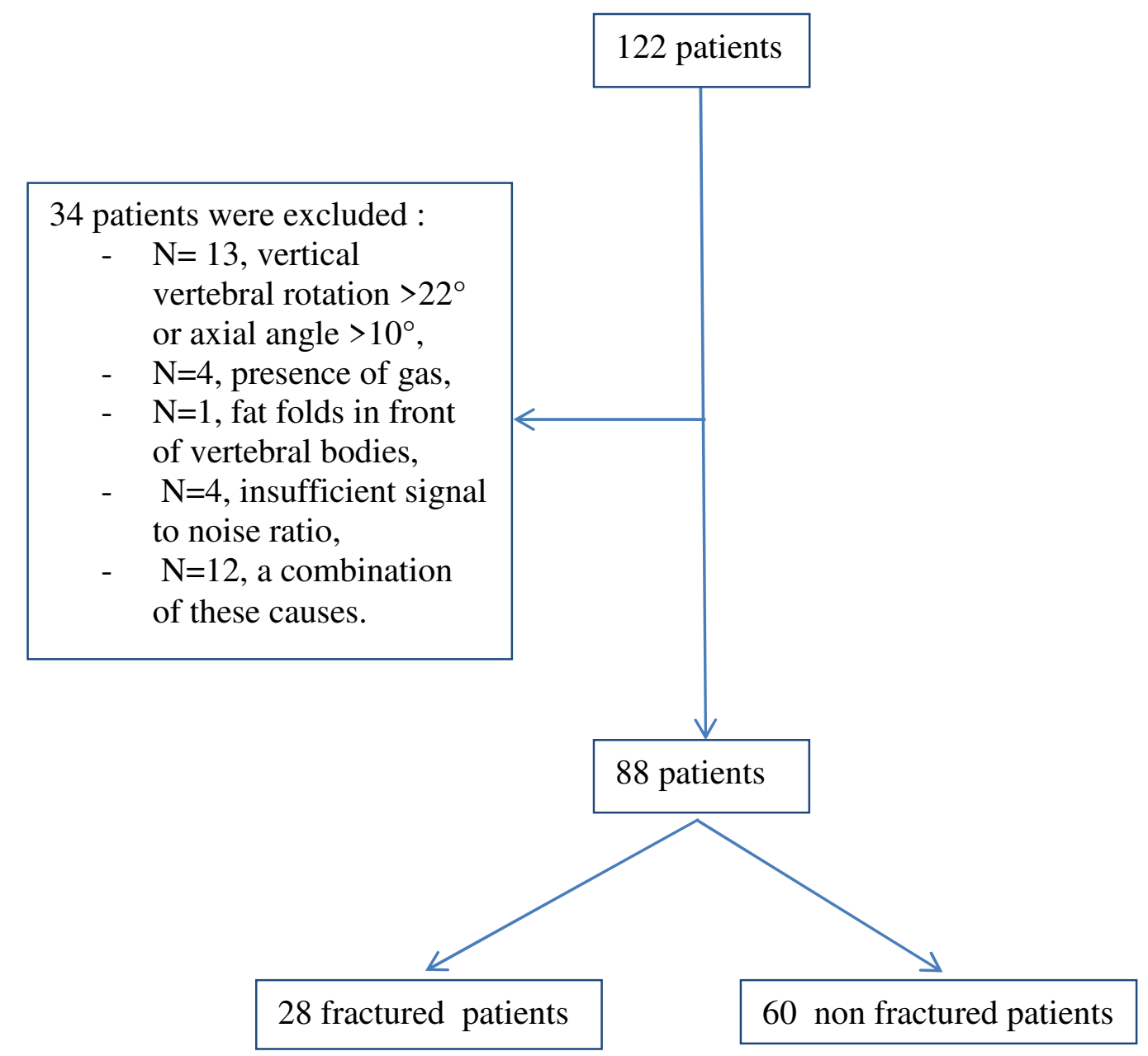


Figure 4: Bland and Altman plot for the effect of positioning on TBS results ( $\mathrm{N}=34$ patients)

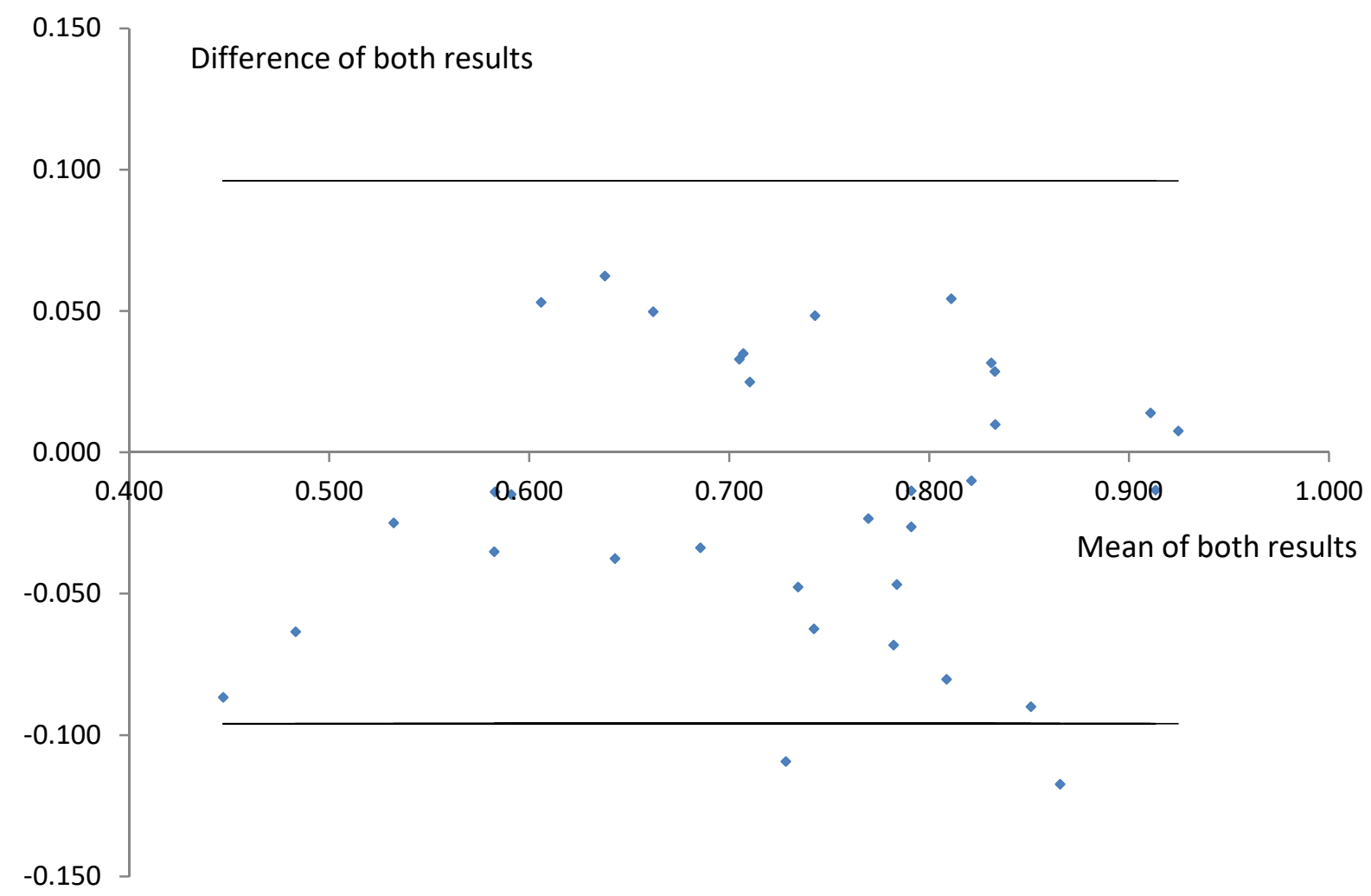


Table 1: Patients characteristics (mean \pm SD)

\begin{tabular}{|l|c|c|c|}
\hline & $\begin{array}{c}\text { Patients with } \\
\text { fractures } \\
(\mathrm{n}=28)\end{array}$ & $\begin{array}{c}\text { Patients without } \\
\text { fractures } \\
(\mathrm{n}=60)\end{array}$ & $\mathrm{p}$ \\
\hline Age (years) & $66.3 \pm 7.48$ & $63.5 \pm 7.94$ & 0.11 \\
\hline Gender (women) (n, \%) & $24(85.7 \%)$ & $57(95.0 \%)$ & 0.14 \\
\hline Weight (kg) & $60.5 \pm 9.4$ & $58.1 \pm 9.6$ & 0.19 \\
\hline Height (cm) & $161.0 \pm 8.3$ & $160.1 \pm 6.8$ & 0.91 \\
\hline BMI (kg/m²) & $23.4 \pm 3.4$ & $22.6 \pm 3.2$ & 0.27 \\
\hline Lumbar spine BMD (L2-L4) & $0.801 \pm 0.137$ & $0.816 \pm 0.145$ & 0.65 \\
\hline Total Hip BMD & $0.734 \pm 0.107$ & $0.727 \pm 0.090$ & 0.59 \\
\hline Femoral neck BMD & $0.597 \pm 0.081$ & $0.611 \pm 0.078$ & 0.65 \\
\hline Osteoporosis prevalence (n,\%) & $18(64.3 \%)$ & $43(71.7 \%)$ & 0.48 \\
\hline TBS-EOS & $0.664 \pm 0.140$ & $0.757 \pm 0.127$ & 0.003 \\
\hline TBS-DXA (L2-L4) & $1.167 \pm 0.085$ & $1.224 \pm 0.098$ & 0.05 \\
\hline
\end{tabular}


Table 2: comparison of different groups of patients according to the number of vertebrae that could be analyzed for TBS-EOS

\begin{tabular}{|l|c|c|c|c|}
\hline & \multicolumn{3}{|c|}{ Number of vertebrae analyzed for TBS-EOS } & \\
\hline & $\begin{array}{c}2 \text { vertebrae } \\
(\mathrm{N}=28)\end{array}$ & $\begin{array}{c}3 \text { vertebrae } \\
(\mathrm{N}=29)\end{array}$ & $\begin{array}{c}4 \text { vertebrae } \\
(\mathrm{N}=31)\end{array}$ & p-value \\
\hline Age & $64.3(8.4)$ & $66.8(7.8)$ & $62.3(6.9)$ & 0.12 \\
\hline Females (N, \%) & $27(96.4 \%)$ & $26(89.7 \%)$ & $28(90.32 \%)$ & 0.58 \\
\hline BMI (kg/m²) & $24.1(3.3)$ & $22.3(3.3)$ & $22.2(2.9)$ & 0.09 \\
\hline $\begin{array}{l}\text { Lumbar Spine } \\
\left.\text { BMD (g/cm }{ }^{2}\right)\end{array}$ & $0.847(0.164)$ & $0.804(0.133)$ & $0.785(0.125)$ & 0.40 \\
\hline $\begin{array}{l}\text { Total Hip BMD } \\
\left.(\mathrm{g} / \mathrm{cm})^{2}\right)\end{array}$ & $0.761(0.098)$ & $0.718(0.091)$ & $0.709(0.091)$ & 0.15 \\
\hline $\begin{array}{l}\text { Femoral Neck } \\
\left.\text { BMD (g/cm }{ }^{2}\right)\end{array}$ & $0.631(0.081)$ & $0.592(0.080)$ & $0.600(0.072)$ & 0.14 \\
\hline $\begin{array}{l}\text { Osteoporosis } \\
(\mathrm{N}, \%)\end{array}$ & $17(60.7 \%)$ & $22(75.9 \%)$ & $22(71.0 \%)$ & 0.45 \\
\hline Fracture (N, \%) & $8(28.6 \%)$ & $8(27.6 \%)$ & $12(38.7 \%)$ & 0.59 \\
\hline TBS EOS & $0.686(0.140)$ & $0.758(0.125)$ & $0.735(0.142)$ & 0.15 \\
\hline TBS DXA & $1.203(0.083)$ & $1.227(0.107)$ & $1.189(0.099)$ & 0.79 \\
\hline
\end{tabular}

